"This is the peer reviewed version of the following article: [Factors influencing nurses' knowledge acquisition of diabetes care and its management: a qualitative study. Journal of Public Affairs, 2018]. which has been published in final form at [http://journals.sagepub.com/doi/full/10.1177/2333393617713097].

This article may be used for non-commercial purposes in accordance with Wiley Terms and Conditions for SelfArchiving." 
MR. ABDULELLAH ALOTAIBI (Orcid ID : 0000-0003-0329-4940)

MRS. ALI HUSSEIN AL-GANMI (Orcid ID : 0000-0002-9894-2121)

Article type : Original Article

\title{
Title Page: Factors influencing nurses' knowledge acquisition of diabetes care and its management: a qualitative study
}

\section{Running Title: Factors influencing nurses' diabetes knowledge acquisition: qualitative study}

\author{
Correspond Author: Abdulellah Alotaibi ${ }^{\text {a b }}$ \\ a PhD candidate, Faculty of Health, University of Technology Sydney (UTS), Australia \\ b \\ Lecturer, Shaqra University, Faculty of Applied Health Science, Saudi Arabia .
}

\section{Co-authors:}

Leila Gholizadeh ${ }^{\text {a }}$

a

Lecturer, Faculty of Health, University of Technology Sydney (UTS), Australia

\author{
Ali Hussein Alek Al-Ganmi ${ }^{\text {a c }}$ \\ ${ }^{\text {a }} \mathrm{PhD}$ candidate, Faculty of Health, University of Technology Sydney (UTS), Australia \\ c Assistant Lecturer, University of Baghdad, College of Nursing, Iraq.
}

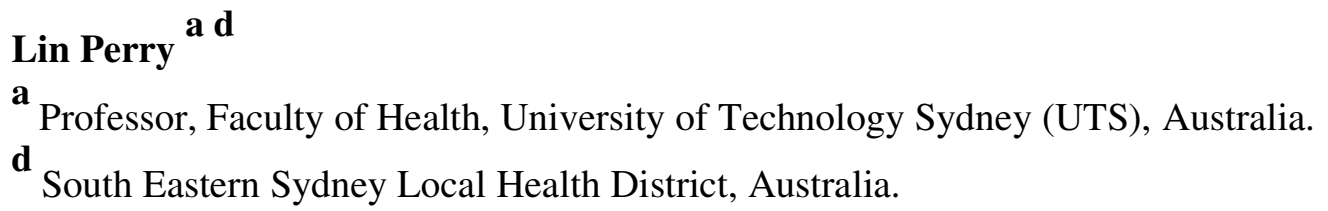

Ali Al-Ganmi: +61408692046; Email: ali.h.al-ganmi@ @student.uts.edu.au

Leila Gholizadeh: +61 29514 4814; Email: Leila.Gholizadeh@uts.edu.au

Lin Perry: +61401771644; Email: Lin.Perry@uts.edu.au

Abdulellah Alotaibi - Corresponding author

Postal Address: P.O. Box 123, Broadway, NSW 2007

Email: abaadi1982@ hotmail.com,2nd Email: Abdulellah.M.Alotaibi@ student.uts.edu.au Phone Number: +61411592913; +966554012000 (Saudi Arabia Mobile)

Author responsible of requests for reprints: Abdulellah Alotaibi

\section{Acknowledgment}

The authors acknowledge Prince Sultan Medical Military City (PSMMC) and the University of Shaqra, Riyadh, Saudi Arabia, who sponsored Dr. Abdulellah Alotaibi PhD program at The University of Technology Sydney. In addition, the authors thank the nurses who participated in the survey.

This article has been accepted for publication and undergone full peer review but has not been through the copyediting, typesetting, pagination and proofreading process, which may lead to differences between this version and the Version of Record. Please cite this article as doi: 10.1111/jocn.14544

This article is protected by copyright. All rights reserved. 


\title{
Conflict of interest
}

The authors declare that there is no conflict of interest relevant to the content of this review.

\section{Funding}

This research received grant from Saudi Arabia Culture Mission (SACM).

\begin{abstract}
Aim: The aim of this qualitative study was to identify and explore the factors nurses perceive as influencing their knowledge acquisition in relation to diabetes care and its management in Saudi Arabia.

Background: Diabetes continues to pose major healthcare challenges despite advances in diabetes management. Nurses have a crucial role in diabetes care but diabetes knowledge deficits deter effective collaboration with other healthcare providers in educating patients about diabetes self-management.

Design: An exploratory descriptive qualitative design.

Method: This qualitative study recruited 16 nurses from different specialty areas at a tertiary hospital in Saudi Arabia. Data were obtained through semi-structured interviews and analysed using thematic analysis.

Results: Three main themes emerged: (1) diabetes care and education (2) barriers affecting nurses' acquisition of diabetes knowledge (3) factors to support nurses' acquisition of diabetes knowledge.

Conclusion: To pursue the goal of continued improvement in diabetes management in the challenging settings of acute care there is a need to develop good practice in diabetes care amongst nursing professionals. Understanding of the complexity of factors that influence nurses' knowledge acquisition in relation to diabetes care and its management provides clinical nurses and nursing mangers with directions for future education, policy development
\end{abstract}

This article is protected by copyright. All rights reserved. 
and research.

Relevance to clinical practice: A range of suggestions are proposed to support development of nursing education and practice in diabetes, including organisational and individual-level strategies to offer and enable access to education programs to maintain up-to-date knowledge and skills in diabetes and effective communication for optimal diabetes self-management.

Keywords: Diabetes, Nurses, Facilitate, Barriers, Education, Knowledge

\section{Introduction}

Diabetes mellitus is a major health concern around the world. It is characterised by high glucose levels in the blood caused by metabolic disturbances (International Diabetes Federation 2015). In the initial stages of the commonest variety (Type 2 diabetes mellitus) this can be controlled by lifestyle modifications that include changes in diet and increasing physical activity, but once diabetes becomes chronic, medication is necessary to control the condition (American Diabetes Association 2015). In 2000 the prevalence of diabetes mellitus was estimated at $2 \%-8 \%$ world-wide, and this is expected to rise to about $10 \%$ by 2030 (International Diabetes Federation 2015). In Saudi Arabia, although socioeconomic developments have resulted in health improvement among the general population, lifestyles have become more sedentary. An increase in meal portion size and an inclination towards fast foods and other diet modifications have led to an increase in obesity, a major risk factor for diabetes. Physical activity and exercise are not a regular part of the daily routine for most Saudi Arabians; as a result, the country has the highest rate of diabetes in the world (AlNozha et al. 2007) and $20 \%$ of the nation's health expenditure is reserved for diabetes (AlNozha et al. 2004, Alotaibi et al. 2017b).

This article is protected by copyright. All rights reserved. 
Living with diabetes requires access to accurate information with education available from health care providers and other reliable sources of information. Multidisciplinary teams need to be able to share information about new health care developments and make decisions regarding the effectiveness and cost-effectiveness of self-management approaches and other health care interventions (Tocchi et al. 2015). The primary goal of diabetes education is to encourage patients to accept their condition, to improve their knowledge and skills in diabetes self-management, and develop problem-solving skills to integrate necessary self-care tasks into their lifestyles (Dunning \& Ward 2008, Funnell et al. 2011). Nurses, as key members of multi-disciplinary diabetes teams, play an essential part in educating patients with diabetes on how to adjust in order to best live the rest of their lives (Hoffman 2013).

\section{Background}

Internationally, nurses working in a variety of health care settings have been shown to have knowledge deficits in all aspects of diabetes care and its management (Alotaibi et al. 2017a, Gerard et al. 2010, Olsen et al. 2012, Yacoub et al. 2014). A study from Saudi Arabia found that nurses had low accuracy in relation to diet/nutrition, diabetes medications, diabetes pathology, symptoms and management (Alotaibi et al. 2017a). They are not unique in this: a Swedish study found that enrolled nurses could not distinguish the different types of diabetes or their symptoms (Olsen et al. 2012), and inadequate knowledge of diabetes medications was found among nurses in the United States and Jordan (Gerard et al. 2010, Yacoub et al. 2014). Nurses indicated that knowledge deficiencies resulted from barriers preventing them achieving full understanding of diabetes. Barriers were reported across different health care settings and identified by both individual nurses and the organisations in which they were employed. Lack of adequate training and education related to diabetes care was highlighted by participants working in Georgia in the United States (Eaton-Spiva \& Day 2011), in

This article is protected by copyright. All rights reserved. 
Australia (Hollis et al. 2014) and in Hong Kong (Shiu \& Wong 2011). Lack of access to educational resources relevant to diabetes care influenced diabetes knowledge acquisition for nurses working in Mauritius, South Africa (Kassean 2005) and Sweden (Olsen et al. 2012). Factors such as lack of diabetes nursing experience was found to affect British and Nigerian nurses' knowledge of and confidence about diabetes care and its management (Nash 2009, Oyetunde \& Famakinwa 2014). Some differences were noted in the barriers encountered by nurses in different countries: while poor attendance at continuing education programs was identified as the main reason for poor diabetes knowledge by British nurses (Nash 2009), nurses working in developing countries were less likely to have access to educational materials and resources and appropriate diabetes training programs (Oyetunde \& Famakinwa 2014). The wider employment milieu was also an influence, with nursing shortages, high workloads and consequent low job morale identified as barriers to nurses' acquisition of adequate diabetes knowledge (Alotaibi et al. 2016, Mutea \& Baker 2008).

Studies have also identified factors that facilitate nurses' diabetes knowledge acquisition and practice. Examples include participation in formal educational programs (Modic et al. 2014), provision of regular diabetes sessions (Gerard et al. 2010), diabetes resources groups, continuing in-service diabetes education, discussion of updates on diabetes care, and provision of resources for bedside nurses (Alotaibi et al. 2016, Gerard et al. 2010). There is, however, limited evidence of which factors facilitate or hinder diabetes knowledge acquisition of nurses in Saudi Arabia. Given the high local prevalence of diabetes, this is important. This study, conducted in a Saudi governmental hospital, offers a first look at the factors influencing nurses' knowledge acquisition in relation to diabetes care and its management and helps to fill this gap in the literature.

This article is protected by copyright. All rights reserved. 


\section{Aim/objectives}

The aim of this qualitative study was to identify and explore the factors nurses perceive as influencing their knowledge acquisition in relation to diabetes care and its management in Saudi Arabia. The specific objectives were to identify and explore the barriers that nurses perceive to hinder their knowledge acquisition in relation to diabetes care and its management, and to identify and explore the facilitators that they perceive to support their knowledge acquisition in relation to diabetes care and management.

\section{Methods}

\section{Design}

This study was part of a larger mixed methods investigation into nurses' knowledge of diabetes and its management in Saudi Arabia. It reports the findings from the qualitative component, which applied an exploratory descriptive approach to elicit detailed insights into the barriers and facilitators of diabetes knowledge acquisition from the perspectives of nurses (Burns \& Grove 2010). An exploratory descriptive qualitative research design is used when there is need to study an issue or problem by seeking the viewpoints of the people most affected but there is difficulty in classifying the research in line with qualitative research traditions, e.g. whether phenomenological, grounded theory or ethnography (Grove et al. 2012).

\section{The research site}

The study was conducted at the Prince Sultan Medical Military City (PSMMC) in Riyadh, Saudi Arabia. This hospital is affiliated with the Ministry of Defence and is the largest referral hospital in Saudi Arabia, with a bed capacity over 1300 covering specialties such as cardiac surgery, primary health care, and medical, surgical, neurology, nephrology, intensive 
care, ear, nose and throat, and urology departments. At the time of this study approximately 3,000 nursing staff were employed in the hospital, $90 \%$ of whom were expatriates from many different nationalities, educational and cultural backgrounds.

\section{Population and sampling}

The study targeted both genders of expatriate and local registered nurses (RNs) employed in the inpatient and outpatient departments at PSMMC. The inclusion criterion was a minimum of six months working in a front-line nursing position in any specialty, because patients with diabetes feature in every area. Nurses were excluded if they worked in managerial positions or in support services without ongoing responsibility for patient care, such as radiology, dialysis, endoscopy or laboratories. Convenience sampling was used to recruit nurses who met the inclusion criterion and were willing to participate. Participants were chosen based on their availability within a range of different nursing subspecialties and their willingness to participate in this study (Onwuegbuzie \& Collins 2007). This sampling approach enabled speedy, easy, and cost effective recruitment (Etikan et al. 2016).

\section{Ethical considerations}

Approvals to conduct this study were obtained from the Hospital Research Centre of Prince Sultan Medical Military City (Project No. 750) and the Human Research Ethics Committee of the University of Technology Sydney (Reference No. 2015000302). Confidentiality was guaranteed to participants, who were free to withdraw from the study at any time.

\section{Recruitment procedures}

Recruitment flyers were posted on the nursing station notice boards of clinical departments at PSMMC, and staff from the Nursing Education and Staff Development Department 
encouraged nurses to participate. Interested nurses were asked to contact the researcher via email. Additionally, information sessions were provided to prospective participants at staff meetings, to explain the study's aims and objectives, the voluntary nature of participation, and what was expected from participants. The researcher's contact details were provided during the sessions and in flyers. Potential participants received a participant information statement, a consent form and socio-demographic data sheet by return email, to be completed and emailed back to the researcher. Participants were then telephoned to arrange dates and times for interviews. The recruitment process continued until data saturation was reached; this was when no new data emerged during interviews. The study recruited nurses from a range of ethnic backgrounds (e.g. Filipino, Saudis); consideration was given in preparation and during the interview to any cultural or religious considerations.

\section{Data collection and management}

Members of the research team jointly developed the interview guide questions, which included: 'Can you tell me how diabetes is managed in this hospital?', 'How would you describe nursing professional practice in managing patients with diabetes?', 'From your point of view, what factors can affect nursing professional practice in managing patients with

diabetes?', 'How can nurses' knowledge of diabetes care and management be improved?', 'What barriers do you think affect nurses' knowledge acquisition of diabetes care and management?' Responses were collected through individual face-to-face in-depth semistructured interviews conducted in English. Data on participants' professional experience, nationality and educational qualifications were collected at this time.

This article is protected by copyright. All rights reserved. 


\section{Pre-interview Stage}

The time and date of each interview was scheduled at the convenience of individual interviewees. They were held in convenient, quiet and private rooms in the hospital to allow participants to comfortably share their views without distraction (Whiting 2008). Arrangements were confirmed with participants the day before the interviews, which lasted about an hour. Consideration was given in preparation and during the interviews to cultural or religious factors. For instance, as the interviewer was male and most interviewees were female, the option of having a third person present was offered. Interviews with female Muslim participants were conducted in the presence of a female nurse from the Nursing Education Department, who signed a confidentiality form prior to the interviews. For Muslim participants, the interviews were arranged for non-prayer times.

\section{Interview Stage}

At the beginning of each interview, the interviewer thanked the interviewee for participating, introduced himself and repeated the purpose and topic to be discussed, and the time available (Laforest et al. 2012). After collecting the participant's consent form, the researcher started the interview, listening attentively and asking probing questions, if necessary. At the end of the interview the researcher summarised what the nurse had said to ensure he had accurately understood the views and experiences presented. The interviews were recorded on a digital audio recorder (Philips DVT-1150 digital voice device) and hand-written notes were taken to assist with analysis of the transcribed data.

This article is protected by copyright. All rights reserved. 
Post-interview Stage

Before concluding each interview, the interviewer checked that all interview topics had been discussed and gave each participant the chance to add any comments or to clarify anything said. The interviewee was thanked again, and the interviewer confirmed that the written notes and audio recordings were completed before closing the interviews (Laforest et al. 2012).

\section{Data analysis}

All the interviews were transcribed verbatim immediately. Transcripts were saved on a password-protected computer to ensure confidentiality, and backed up to prevent data loss. Qualitative data were entered into the software program NVivo Version 11 and analysed using thematic analysis, conducted in the six steps prescribed by Braun and Clarke (2006) (See Table 1). The transcripts were first open coded (labelled), then axial coded (categorised) and thematically analysed. The researcher and supervisors reviewed the codes and discussed the categories and themes to ensure that the participants' perspectives were accurately and appropriately represented. Identification codes were developed based on each participant's current specialty in order to label verbatim quotes without breaking confidentiality.

\section{Trustworthiness}

Trustworthiness was managed in this study following Lincoln and Guba's (1985) framework of creditability, dependability, confirmability and transferability. The researcher used a number of strategies: a soft copy of their personal transcript was sent to each participant by email and they were asked to read and confirm the content or to add comments or clarification. The interviewer debriefed the research team during the data collection and analysis. The process of transcribing and coding data was described, discussed, and reported in detail. The results, interpretations and conclusions were audited through the research team

This article is protected by copyright. All rights reserved. 
to ensure that a clear and transparent research process was followed. The team listened to the recordings of the interviews to confirm the accuracy and relevance of the primary data and analyses. The depth and breadth of the descriptions and explanations of the results was presented in this study to enable readers to judge its transferability to other contexts.

\section{Results}

Data saturation was reached after 16 semi-structured interviews with RNs working in a variety of settings. Twelve participants were female $(81.3 \%)$ and four were male $(18.8 \%)$; all were aged between 30 and 50 years (with a mean age of 33 years), and most had nursing experience ranging from 6 to 11 years $(62.5 \%)$. More than half the participants $(56 \%)$ were from the Philippines; all held at least a bachelor's degree in nursing science (See Table 2). The findings of the study were organised under three main themes: diabetes care and education; barriers affecting nurses' acquisition of diabetes knowledge; and factors supporting nurses' acquisition of diabetes knowledge (See Table 3).

\section{Diabetes care and education}

Participants believed that caring for and educating patients with diabetes required a multidisciplinary team with knowledge of different aspects of diabetes care (e.g. diet instruction, medication management, and other aspects of holistic care). The nurses felt that they should have a major role in diabetes care and education, since they are the predominant group that asks about, listens to and notes patients' care needs, spending more time with hospitalised patients than any other professional health care group, including physicians or diabetes specialists (e.g. diabetes educators, dieticians). They felt it was important for patients to be able to make use of this degree of contact to update and consolidate their knowledge for diabetes self-management. However, they found their roles overlapped those of other 
diabetes care providers: for example, diet instruction was also given by dieticians; diabetes educators also taught patients about checking blood glucose levels and taking diabetes medications. This gave rise to two sub-themes: the reality of their role in diabetes care, and overlapping diabetes care and education.

\section{The reality of the nursing role in diabetes care}

Nurses in this study took care of patients with diabetes whether they were admitted to hospital for reasons directly related or incidental to their diabetes. They described the reality of their nursing role in diabetes care as contributing to the initial patient assessment, administering diabetes medications, and implementing treatment plans as ordered by the physician or other diabetes care providers. It was also their responsibility to identify patients who did not adhere to their prescribed medications and diabetes diet plans, and to refer these patients to a dietician or diabetes educator for further education and reinforcement. Nurses felt they were side-lined and did not play a big part in the diabetes team.

From the neonatal clinic, patients are already aware and educated about diabetes when they come up here to our ward; nurse role is to make sure that they comply with the diabetes plan given by dieticians or diabetes educators in relation to the diabetes treatment and stick to diabetic diet. (Obstetric/Gynaecology nurse)

Nurses talked about their role in relation to the practical aspects of diabetes care, such as controlling and monitoring blood glucose levels, documenting the results in a sliding scale form, and informing the doctor to review any patient whose blood sugar level was not within the recommended range. Most nurses felt that their role was restricted to practical aspects such as checking and observing blood glucose levels.

This article is protected by copyright. All rights reserved. 
Nurse usually check, observe and write the blood sugar level every six hours unless the doctor ordered hourly check. (ENT nurse)

Many nurses believed that the reality of their nursing role in diabetes care was to follow hospital policies and specialist team instructions regarding diabetes treatment plans. For example, they assessed patients for diabetes complications such as diabetic wounds or ulcers, and followed the wound care team's plans in dressing patients' wounds, or they administered insulin as prescribed on medication charts with consideration of the patients' blood glucose levels. Prior to discharge, diabetes educators and other specialists (such as the wound care team, as appropriate) took over and assumed full responsibility for educating patients about diabetes self-management.

My role in managing a patient with diabetes is that I give instructions to the patient; like, for example, give insulin and diabetes medications to them depending on their blood sugar level, and proper hygiene and sterile dressing if there is open wound. (Nephrology nurse)

The nurses reported following the hospital's policies and procedures for diabetes care. They were aware of their roles in diabetes nursing management, which were intended to dovetail with, rather than overlap, the work of other health care providers such as diabetes educators and dieticians; in reality they reported having little or no opportunity to be involved in educating diabetes patients about self-care and diet. They felt that their role in providing diabetes education was eroded by the work of other team members with specialist roles, and that ambiguous wording in their job descriptions served to limit nurses in their understanding of their full role.

This article is protected by copyright. All rights reserved. 


\section{Overlapping diabetes care and education}

Some aspects of the nurses' roles in diabetes care and education overlapped those of other multidisciplinary team members. For example, they noted that dieticians were fully responsible for providing diet instruction, and other elements of holistic care for patients with diabetes were divided between nurses and diabetes educators. The nurses felt they had limited authority to educate patients with diabetes in regard to diet planning, and were only authorised to refer patients to a dietician for intensive dietary instructions and consultation. They noted that dieticians were available in every in-patient department and were responsible for educating patients and coordinating their diet plans.

Nurses inform dieticians in each assigned area to see patients with diabetes in order to control, coordinate and educate patients about diabetes diet. (Neurosurgery nurse)

Nurses stated that diabetes educators had the primary responsibility for provision of diabetes self-care management and education. This included ensuring that patients had a sound understanding of diabetes and received the support they needed to make informed lifestyle and treatment choices, such as to incorporate physical activity into their daily life, and to adhere to their medication regimens. Some respondents claimed that it was the responsibility of diabetes educators to educate patients with diabetes about how to use diabetes medications and about insulin injections before discharge. Nurses explained that they would call diabetes educators if patients with diabetes required extensive self-management education in relation to diabetes care in business working hours. Nurses themselves played only a small role in education of diabetes patients - on public holidays and after-hours, when dieticians and diabetes educators were not available. In this case, they documented patients' educational needs in their medical records and followed up with a referral of the patients to an on-call dietician or diabetes educator.

This article is protected by copyright. All rights reserved. 
Truly, there's a person responsible (for patient education), the diabetes educators are responsible to educate the patient. We're only assisting the patient and giving regular medications. We're only calling them to educate the patient. Diabetic educators are the ones advising, instructing the patient prior to discharge as well as teaching the patient how to inject the insulin, to take oral medication and to use machine for checking blood glucose level by themselves. (Nephrology nurse)

These nurses felt they were not authorised or enabled to educate patients with diabetes in relation to different aspects of diabetes care. Due to the overlapping of their role in patient education with that of diabetes educators, nurses felt that their authority and space for providing diabetes care was reduced.

\section{Barriers affecting nurses' acquisition of diabetes knowledge}

Nurses were clear that they have an important role in caring for the increasing number of patients with diabetes. To support these patients effectively, nurses require comprehensive understanding of all aspects of diabetes care and treatment. However, nurses in this study identified various barriers to improving their diabetes knowledge, at both individual and organisational levels.

\section{Barriers at an individual level}

Some participants expressed a lack of interest in gaining new knowledge because they felt that diabetes care was long-term, and that more education and knowledge in individual nurses would not lead to better outcomes. A few nurses working in acute care specialties believed that there was no reason to update their diabetes knowledge because they thought of the disease as a chronic condition with no cure:

This article is protected by copyright. All rights reserved. 
Nurses just do it as routine because diabetes is long-term care and a common disease in Saudi Arabia, which causes lack of interest among nurses to improve their knowledge of diabetes care. (Neurosurgery nurse)

In addition, nurses claimed that they did not have time to attend available diabetes continuing education programs, especially those scheduled out of work hours. Feeling tired after work and having family responsibilities were individual-level barriers to participation in education highlighted by some respondents. Nurses who were close to retiring expressed a lack of motivation in keeping themselves up to date with diabetes care. In addition, age was believed to be a factor affecting some nurses' capacity, both physically and intellectually, to acquire new knowledge. Some nurses claimed that 'older nurses', pre-retirement, were unwilling to update their knowledge of diabetes management, which was consequently out-dated.

For example, one thing is age. If you are already old, I will just sit and lie down at home. Why should I attend the study days? I'm very tired of working ... I spend my day off just to relax. (Cardiology nurse)

Lack of clinical experience was identified as another individual-level barrier. Junior nurses claimed that they had knowledge deficits in diabetes care, particularly diabetes foot care and management of severely ill diabetes patients including those in coma, as they were not generally involved in the care of diabetes patients. Lack of previous experience and perceived knowledge deficits were viewed by junior nurses as affecting their confidence in providing care to diabetes patients:

If I'm a newly hired staff...just passed the board exam, I don't have much experience about diabetes care. I don't have any experience in seeing patients with diabetes ... the experience about the complications of it and how it is managed. It affects my care of patients. If I'm just new, of course I don't have much experience, so maybe the care would not be that excellent. (ENT nurse)

This article is protected by copyright. All rights reserved. 
A few nurses also raised personal concerns, such as family-related issues. Many expatriate nurses experienced problems such as stress and homesickness that influenced their knowledge and practice, the standard of diabetes care they delivered, and their capacity to acquire diabetes knowledge. Some nurses argued that more professional assistance and motivation from senior nurse colleagues and nursing managers would have a positive impact on their wellbeing, and would promote more positive attitudes to safe and up-to-date practice amongst nurses:

The head nurse or supervisor is not motivating you that much or encouraging you to learn new things. Why would you read if you don't have the mood to study? For example, if you have a family problem, do you think you have the time to read? Of course you don't. (Surgical nurse)

\section{Barriers at an organisational level}

Most nurses identified organisations barriers related to the acquisition of diabetes knowledge, including lack of resources, lack of access to relevant information, lack of opportunities due to staff shortages and high workloads, lack of institutional support, motivation or incentives, and difficulty interacting with other members of the multidisciplinary team. While nurses in medical departments had access to regular, continuing diabetes education, many of those in non-medical specialties reported a lack of diabetes information resources, such as pamphlets, posters and guidelines, as an on-going challenge; they did not even have sufficient diabetesrelated resources for the patients with diabetes in their care:

We don't have enough resources in our department to properly manage and educate patients. If we had sufficient resources, we could do it. These resources are provided only to the endocrinology department. (Neuroscience nurse)

This article is protected by copyright. All rights reserved. 
Many nurses said that they missed continuing educational opportunities because they were not informed about the time and venue of these programs, and believed that these opportunities were neither advertised nor arranged appropriately:

Head nurses do not tell their nurses about planned diabetes in-service education programs, even nurses on the ward on the day of the programs. The only time we know about in-service training is via the intranet. In addition to the absence of direct notices, no one tells us that we need really to attend in-service diabetes programs. (Neurology nurse)

Many said they were willing to increase their diabetes knowledge and skills by reading electronic guidelines and attending diabetes education sessions and workshops provided by the nursing education and staff development unit

The provision of Internet access in nurses' flats and guidelines online would enable nurses to update their diabetes-related knowledge. (Oncology nurse)

Nurses in different specialties had differing perspectives of the quality of the existing diabetes educational programs. Some believed they had gained little or no knowledge from the programs they had attended, citing poor content, poor presentation or communication skills of the educator. Some felt that a lack of specialist lecturers in this field affected the quality of the education provided:

Yeah, the hospital management usually provides lectures and study days every year. However, they don't always have professionals to present the lecture or oversee the study days. (Paediatric nurse)

This article is protected by copyright. All rights reserved. 
The nurse-patient ratio at the unit level was another major concern for nurses, perceived as having a negative impact on nursing education and development. Heavy workloads affected their ability to take part in relevant sessions/workshops inside or outside the hospital:

In our hospital, we handle four to six critical cases every shift. We're too busy with patient care to discuss diabetes control with the patient. We can't attend workshops inside or outside the hospital due to our workload and shortage of staff. (Orthopaedic and Ophthalmology nurse)

A few nurses also reported difficulties interacting with members of the multidisciplinary health care team because of poor inter-professional communication. For instance, they reported that some physicians disrespected the nurses in clinical settings and took no account of their opinions about diabetes care, making it difficult for nurses to speak for their patients:

Sometimes, some of the doctors are very dominant. They ask the nurses unprofessionally, like they raise their voice, interrupt them; of course if you are going to talk to them in that way I am not going to talk with you properly what is happening with the patient.

(Cardiology nurse)

\section{Factors to improve nurses' acquisition of diabetes knowledge}

Organisational factors to enhance diabetes knowledge

The majority of nurses believed that the organisation played an important role in improving nurses' knowledge of diabetes care by organising workshops and seminars. Managers' support for nurses to participate in continuing diabetes education and training was perceived as a priority, as was the introduction of an information dissemination system and improving institutional resources, such as staffing numbers and expertise. Nurses considered that making printed learning materials available in the hospital wards would facilitate updating of

This article is protected by copyright. All rights reserved. 
their diabetes knowledge and practice and help close knowledge gaps in different aspects of diabetes care.

If diabetes resources and materials were provided to the different departments to educate nurses as well as patients, these would help nurses improve their diabetesrelated knowledge and diabetes care skills. (Neuroscience and Urology nurse)

Nurses believed that the provision of high-quality continuing diabetes education and inservice training programs by expert educators would enable them to improve their knowledge of diabetes care and management and make them better nurses. A few suggested that the provision of education sessions by nurse educators on pharmacological and nonpharmacological diabetes treatment was essential to improve nurses' knowledge of diabetes management:

The provision of incentives would encourage nurses to attend these programs or symposiums. Of course, if they are free! (ENT nurse)

Nurses reported that increasing institutional resources was conducive to knowledge building and knowledge acquisition of diabetes care and management. They also highlighted that local guidelines and protocols, in addition to institutional support and motivation, would facilitate nurses' ability and willingness to update their knowledge and management of diabetes. Somewhat simplistically, perhaps, the implementation of common guidelines and protocols was identified as important to guide the care of diabetes patients:

If we all follow the same guidelines and protocols, we will be able to provide good nursing care to the diabetic patient. (Paediatric nurse)

This article is protected by copyright. All rights reserved. 


\section{Environmental factors to enhance diabetes knowledge}

It was considered important that the members of multidisciplinary teams have opportunities to talk to each other about diabetes care and exchange information and experiences. Considering the local environment and ward culture, nurses perceived that putting processes in place for professional interaction and knowledge exchange between nurses and other diabetes care providers was necessary to provide quality diabetes care and management. They felt that such processes would encourage good working relationships among all diabetes care providers, and support knowledge sharing in relation to diabetes care; would encourage nurses to be present at ward rounds and facilitate the exchange of diabetes-related knowledge with other health care professionals. Such professional interaction would provide opportunities for nurses to discuss or ask questions about patient care and to update their knowledge about medications, diabetes pathophysiology or other aspects of care:

Multi-disciplinary team interaction is important in diabetes care. If there is a problem, the team members will be able to share their knowledge. If one person has insufficient diabetes knowledge, the other members of the multi-disciplinary team can fill that gap, and the others can learn from that person. (ICU and Emergency nurse)

\section{Discussion}

This is the first study conducted in Saudi Arabia to explore the factors influencing nurses' knowledge acquisition in diabetes care and its management, a topic that will only become more important in coming years, given the high and rising prevalence of diabetes in the country (Alotaibi et al. 2017b). However, this study found a lack of clarity, caused by overlapping roles in diabetes care and education between nurses and other diabetes care providers, and conflicting attitudes amongst nurses that could lead to misinformation and misconceptions about diabetes care.

This article is protected by copyright. All rights reserved. 
Nurses mainly described themselves as responsible for the practical aspects of diabetes care rather than being involved in patient education, a responsibility mainly placed on dieticians, diabetes educators and other multi-disciplinary team members. Similar experiences have been reported elsewhere. A Canadian study that explored inter-professional collaboration in diabetes care found poor interaction between dieticians, diabetes educators and nurses caused by overlapping or shared role boundaries (Gucciardi et al. 2016). This situation appeared to strongly influence the attitudes of the nurses towards diabetes care and patient education, which may also be the case not only in Saudi Arabia but in other parts of the world (Dubois \& Singh 2009, Eijkelberg et al. 2003).

The varying nature of inter-professional role boundaries and the scope of practice of specialist diabetes educators and nurses may mean that the roles of different members of the health care team are not clearly understood, particularly in a multi-national workforce. The nurses in this study reported widely varying attitudes, with evidence of uncertainty and ambivalence about what their roles could, should and did entail. This lack of role clarity and definition may perhaps have contributed to the low motivation to improve their diabetes knowledge reported by some participants. This reinforces the importance of role clarity for each profession, irrespective of the nationality of origin, so that nurses are confident and can develop competence in their specific responsibilities and know when to refer the patient to which other diabetes specialist. Better understanding is required of local job descriptions, specifically related to diabetes management, by all members of the health care team to prevent overstepping or gaps in responsibilities, and to improve autonomy of practice (Braithwaite et al. 2012). Nurses have historically provided the principle diabetes education but they need to be equipped with adequate knowledge of diabetes care in order to be effective (King et al. 2017). Many nurses saw their roles in relation to diabetes care and education as eroded and limited by other diabetes specialists, yet asked for multidisciplinary

This article is protected by copyright. All rights reserved. 
collaboration as a way to enhance their knowledge of diabetes care. A multidisciplinary team approach is best suited for diabetes care, to achieve the high demands of patients, utilise the best diabetes resources, and provide positive measurable outcomes (Codispoti et al. 2004).

Nurses recognised their limited knowledge regarding diabetes-self-management, and felt that this limited their roles in diabetes care. Empowerment skills support the educational performance of nurses by making them aware of the significance of patient education to resolve patients' needs as well as to boost self-confidence and create strategies for mutual trust with other multi-disciplinary team members involved in diabetes care (Aslani et al. 2016, Tol et al. 2015). The role of nurses in the diabetes care team is vital because of their regular contact with the patient (Aalaa et al. 2012). Not all nurses interviewed were, or perceived other nurses as, motivated to learn. However, given their $24 / 7$ presence and monitoring function, nurses necessarily serve as the out-of-hours and weekend 'safety net' for patient education and care. They need to be knowledgeable to fulfil this duty, and this can be achieved through continuing education and effective inter- and intra-disciplinary teamwork and collaboration (Young 2011). Studies suggest that the content, amount, relevance and complexity of nurses' knowledge plays a critical role in the impact of education for patients (Fabrigar et al. 2006). Provision of education does not guarantee good nursing practice, but knowledge is a necessary precursor of behaviour and the influence of knowledge on a person's attitudes and behaviours is well established (Curtis et al. 2017). There is an association between nurses' educational achievement and their clinical competence (Cruz 2017). Deficiencies in nurses' diabetes knowledge may contribute to development of negative attitudes towards diabetes care, which may further translate into poor nursing practice in diabetes care (Curtis et al. 2017). Future studies of the effect of nurses' knowledge on their competence in providing diabetes care should test this 
assumption. Some (but not all) nurses saw a need for, and believed that they should have, a wider role in patient education. Given the high and rising prevalence of diabetes in Saudi Arabia and worldwide (Alotaibi et al. 2017b) and its strong links to behavioural risk factors, involving members of the multi-disciplinary team is important for the effective management of diabetes.

There were some misperceptions about diabetes management among nurses in this study. Some viewed diabetes as a chronic condition with no cure and did not believe that nurses' knowledge or patient education could do any better for disease management. These misconceptions about diabetes management among health care professionals need to be addressed. Many barriers to managing diabetes and educating patients with diabetes were determined from the perspectives of these nurses; many have also been identified in other studies from other nations (Kassean 2005, Oyetunde \& Famakinwa 2014). Many issues can deter nurses from fulfilling their potential role in care of patients with diabetes, from lack of access to high-quality in-service education and training, through perceived limitations in managerial support, to the personal and professional issues of a largely multi-national, expatriate workforce. As a professional group, the nurses in this study reported many barriers and appeared fundamentally conflicted in their attitudes to diabetes care: in the importance they accorded this, and in relation to their motivation to update their diabetes knowledge. Many appeared to lack understanding and appreciation of the impact of diabetes as a disease spanning acute and life-threatening events through to life-style related disorder, none of which can be managed without good knowledge of diabetes in health professionals and effective involvement of patients in self-care activities (Mensing et al. 2004).

This article is protected by copyright. All rights reserved. 
A vicious cycle is in evidence: lack of motivation or access to up-to-date diabetes information results in poor and out-dated knowledge, attitude and practices, which perhaps are the source of the physicians' poor regard for nurses' knowledge which so demotivated some nurses (Amsalu et al. 2014). Lack of effective multi-disciplinary collaboration, and disrespect from physicians, is clearly a disincentive to nurses to contribute to case discussions; possibly to further diabetes education (Burgess \& Purkis 2010). There are clearly very real workload barriers, but few nurses anywhere, worldwide, would not report this as an issue (Mwebaza et al. 2014). Inadequate diabetes education programs, lack of institutional support and materials, heavy workloads and shortages of nursing staff have also been identified in studies from UK, the United States, Australia, Jordan and Nigeria (Alotaibi et al. 2016).

The classification of other nurses by some young nurses as 'too old' or 'too tired' to learn seems extraordinary. Young but inexperienced nurses were more willing to acquire new diabetes care knowledge and skills, and these nurses might be the role models to empower other nurses to provide better diabetes care and improve patient health outcomes (Aslani et al. 2016). Nurses' lack of interest in obtaining new knowledge accompanied by lack of encouragement and motivation from nursing managers was also reported by Atefi et al. (2014) in Iran. In this study, a number of strategies were suggested to improve nurses' knowledge in relation to delivery of diabetes care and education. Supportive nursing management was thought likely to result in better diabetes education and care among nurses, while lack of attention to nurses' own problems (e.g. workload) might have the opposite effect (Farsi et al. 2010). Nurse managers have a role to play in creating a positive work environment, influencing nurses by motivating and encouraging them to improve their diabetes knowledge, involving nurses in policy-making, especially where policies affect nursing staff directly and may enhance or detract from nurses' diabetes knowledge (de

This article is protected by copyright. All rights reserved. 
Oliveira et al. 2015). Effective inter- and intra-professional communication and collaboration and diabetes knowledge exchange could be effective; even the simple availability of printed learning materials, and increasing institutional resources and support for continuing diabetes education and training (Gerard et al. 2010, Modic et al. 2014).

Effective collaboration of nurses with other health care teams is important for improving diabetes care (Rejeh et al. 2008). In a rapidly changing field such as diabetes, continuing education is essential to support nurses' knowledge of diabetes care and education (Gerard et al. 2010), and to provide nurses with empowerment skills to effectively involve patients in their treatment processes and self-care activities (Tol et al. 2015).

These findings make clear that, with barriers operational at both the individual and organisational levels, initiatives to redress deficits in nurses' diabetes knowledge also need to operate at both levels. Organisations need systems to monitor local care processes and patient outcomes, to inform managers on practice performance in relation to established 'best practice' and how this relates to patient outcomes. This could encourage organisations to prioritise development of diabetes care polices and education programs (Atefi et al. 2014, Rejeh et al. 2008) and enable development of targeted improvement plans and contribute to better performance indicators. Individuals need a clear understanding what is expected of their and other healthcare professionals' roles; access to education and training to ensure they maintain adequate up-to-date knowledge to deliver this, and respect for each others' contributions to diabetes team care.

\section{Limitations of the study}

The analysis of interview data in this study led to the identification of barriers and facilitators to nurses' acquisition of diabetes knowledge. In considering the transferability of these findings to the wider population of nurses, the origin of the research in a single hospital, and

This article is protected by copyright. All rights reserved. 
the particular characteristics of that research site, should be born in mind. All interviews with Muslim female nurses were attended by a female member of the nursing education department, and this may have limited open discussion of personal and organisational barriers to diabetes knowledge by these nurses. Further exploration of nurses' diabetes knowledge acquisition and their role in diabetes is required, to include the perspectives of other members of the diabetes team (educators, dieticians, physicians and managers, for example), and of the patients and families themselves. Broader recruitment across other sites and specialty groups could develop the breadth of understanding of this topic.

\section{Conclusion}

The findings of this study provide insights into factors that affect nurses' knowledge acquisition related to diabetes care, and flag opportunities for future translational research to determine how 'best practice' diabetes care can be developed amongst a nursing workforce such as this. Nurses confront many obstacles to improving their diabetes knowledge, which include both personal and organisational barriers, and require an empowerment program through, for example, action research, which can result in change and improvement in the nurses' knowledge and practice in relation to diabetes care (Aslani et al. 2016). Such programs should address attitudes and beliefs among nurses regarding diabetes management, and nurses should be supported to develop a rational and consistent view of the role that their knowledge, attitudes, and practice can play in diabetes management. In addition, nurses' diabetes knowledge may be improved by changes to policies, in relation to job descriptions and role clarity, inter- and intra-professional communication; and by changes to practice, in terms of the availability of diabetes resources and managerial practices in human resource management and access to continuing education. High quality, well-organised, accessible continuing education programs and in-service courses are clearly an essential component to 
improve nurses' knowledge about diabetes care and its management. When multipledisciplinary work together in diabetes care they can deliver comprehensive care and address the patients' needs better.

\section{Relevance to clinical practice}

Diabetes is a significant health issue globally. As the largest group of health care professionals, nurses should be actively and professionally engaged in multidisciplinary collaboration to effectively address prevention and management of diabetes. The findings of this study can help to inform policies and guidelines for diabetes care and management for safe implementation of nursing practice. It also can support those who design nursing curricula to shape the nursing role in diabetes care and education. Further research is needed to explore how best to enable nurse education in diabetes care, for the development of nursing practice and patient education. More professional development opportunities for nurses should be offered to increase nurses' knowledge and practice in relation to diabetes care, and ways to encourage uptake explored, including, for example, mandatory up-dating to maintain registration. Overall, the outcomes reported here provide important insights for policy makers on how to improve the quality of healthcare and job satisfaction.

This article is protected by copyright. All rights reserved. 


\section{REFERENCES}

Aalaa M, Malazy OT, Sanjari M, Peimani M \& Mohajeri-Tehrani MR (2012): Nurses' role in diabetic foot prevention and care; a review. Journal of Diabetes \& Metabolic Disorders 11, 1-6.

Al-Nozha MM, Al-Hazzaa HM, Arafah MR, Al-Khadra A, Al-Mazrou YY, Al-Maatouq MA, Khan NB, Al-Marzouki K, Al-Harthi SS \& Abdullah M (2007): Prevalence of physical activity and inactivity among Saudis aged 30-70 years: a population-based cross-sectional study. Saudi medical journal 28, 559-568.

Al-Nozha MM, Al-Maatouq MA, Al-Mazrou YY \& Al-Harthi SS (2004): Diabetes mellitus in Saudi Arabia. Saudi medical journal Vol. 25 1603-1610.

Alotaibi A, Al-Ganmi A, Gholizadeh L \& Perry L (2016): Diabetes knowledge of nurses in different countries: An integrative review. Nurse education today 39, 32-49.

Alotaibi A, Gholizadeh L, Al-Ganmi A \& Perry L (2017a): Examining perceived and actual diabetes knowledge among nurses working in a tertiary hospital. Applied nursing research 35, 24-29.

Alotaibi A, Perry L, Gholizadeh L \& Al-Ganmi A (2017b): Incidence and prevalence rates of diabetes mellitus in Saudi Arabia: An overview. Journal of Epidemiology and Global Health 7, 211-218.

American Diabetes Association (2015) American Diabetes Association Standards of Medical Care in Diabetes Available at: http://professional.diabetes.org/admin/userfiles/0 - sean/documents/january supplement combined_final.pdf (accessed 12 June 2015).

Amsalu E, Boru B, Getahun F \& Tulu B (2014): Attitudes of nurses and physicians towards nurse-physician collaboration in northwest Ethiopia: a hospital based cross-sectional study. BMC nursing 13, 13-37.

Aslani Z, Alimohammadi N, Taleghani F \& Khorasani P (2016): Nurses' Empowerment in Self-Care Education to Stroke Patients: An Action Research Study. International journal of community based nursing and midwifery 4, 329-338.

Atefi N, Abdullah K, Wong L \& Mazlom R (2014): Factors influencing registered nurses perception of their overall job satisfaction: a qualitative study. Int Nurs Rev 61, 352360.

Braithwaite J, Westbrook M, Nugus P, Greenfield D, Travaglia J, Runciman W, Foxwell AR, Boyce RA, Devinney T \& Westbrook J (2012): Continuing differences between health professions' attitudes: the saga of accomplishing systems-wide interprofessionalism. International Journal for Quality in Health Care 25, 8-15.

Burgess J \& Purkis ME (2010): The power and politics of collaboration in nurse practitioner role development. Nursing Inquiry 17, 297-308.

Burns N \& Grove SK (2010) Understanding nursing research: Building an evidence-based practice. Elsevier Health Sciences.

Codispoti C, Douglas MR, McCallister T \& Zuniga A (2004): The use of a multidisciplinary team care approach to improve glycemic control and quality of life by the prevention of complications among diabetic patients. The Journal of the Oklahoma State Medical Association 97, 201-204.

Cruz JP (2017): Quality of life and its influence on clinical competence among nurses: a self - reported study. Journal of clinical nursing 26, 388-399.

Curtis K, Fry M, Shaban RZ \& Considine J (2017): Translating research findings to clinical nursing practice. Journal of clinical nursing 26, 862-872.

de Oliveira FP, Mazzaia MC \& Marcolan JF (2015): Sintomas de depressão e fatores intervenientes entre enfermeiros de serviço hospitalar de emergência. Acta Paulista de

This article is protected by copyright. All rights reserved. 
Enfermagem 28, 209-215.

Dubois C-A \& Singh D (2009): From staff-mix to skill-mix and beyond: towards a systemic approach to health workforce management. Human resources for health 7, 87.

Dunning T \& Ward G (2008) Managing clinical problems in diabetes. John Wiley \& Sons.

Eaton-Spiva L \& Day A (2011): Effectiveness of a computerized educational module on nurses' knowledge and confidence level related to diabetes. Journal for Nurses in Staff Development - JNSD 27, 285-289.

Eijkelberg IM, Spreeuwenberg C, Wolffenbuttel BH, van Wilderen LJ \& Mur-Veeman IM (2003): Nurse-led shared care diabetes projects: lessons from the nurses' viewpoint. Health Policy 66, 11-27.

Etikan I, Musa SA \& Alkassim RS (2016): Comparison of convenience sampling and purposive sampling. American Journal of Theoretical and Applied Statistics 5, 1-4.

Fabrigar LR, Petty RE, Smith SM \& Crites Jr SL (2006): Understanding knowledge effects on attitude-behavior consistency: The role of relevance, complexity, and amount of knowledge. Journal of Personality and Social Psychology 90, 556-577.

Farsi Z, Dehghan N, Negarandeh R \& Broomand S (2010): Nursing profession in Iran: an overview of opportunities and challenges. Japan journal of nursing science 7, 9-18.

Funnell MM, Brown TL, Childs BP, Haas LB, Hosey GM, Jensen B, Maryniuk M, Peyrot M, Piette JD \& Reader D (2011): National standards for diabetes self-management education. Diabetes Care 34, S89-S96.

Gerard SO, Griffin MQ \& Fitzpatrick J (2010): Advancing quality diabetes education through evidence and innovation. J Nurs Care Qual 25, 160-167.

Grove SK, Burns N \& Gray J (2012) The practice of nursing research: Appraisal, synthesis, and generation of evidence. Elsevier Health Sciences.

Gucciardi E, Espin S, Morganti A \& Dorado L (2016): Exploring interprofessional collaboration during the integration of diabetes teams into primary care. BMC Family Practice 17, 12.

Hoffman AJ (2013): Enhancing self-efficacy for optimized patient outcomes through the theory of symptom self-management. Cancer nursing 36, E16-26.

Hollis M, Glaister K \& Lapsley JA (2014): Do practice nurses have the knowledge to provide diabetes self-management education? Contemporary Nurse : a Journal for the Australian Nursing Profession 46, 234-241.

International Diabetes Federation (2015) IDF Diabetes Atlas (7th ed). Available at: http://www.idf.org/sites/default/files/EN_6E_Atlas_Full_0.pdf (accessed July $20162015)$.

Kassean HK (2005): Nurses' perceptions of their role in caring for diabetic patients at the primary care level: a case study from Mauritius. Journal of Health Management 7, 207-217.

King O, Nancarrow S, Grace S \& Borthwick A (2017): Diabetes educator role boundaries in Australia: a documentary analysis. Journal of Foot and Ankle Research 10, 28.

Laforest J, Bouchard L-M \& Maurice P (2012) Guide to organizing semi-structured interviews with key informants: Safety diagnosis tool kit for local communities. Institut national de santé publique Québec avec la collaboration de Ministère de la sécurité publique.

Mensing C, Boucher J, Cypress M \& Weinger K (2004): National standards for diabetes selfmanagement education. Diabetes Care 27, S143-S143.

Modic MB, Vanderbilt A, Siedlecki SL, Sauvey R, Kaser N \& Yager C (2014): Diabetes management unawareness: what do bedside nurses know? Applied nursing research 27, 157-161.

Mutea NK \& Baker CM (2008): Kenyan nurses' involvement in managing hospitalized

This article is protected by copyright. All rights reserved. 
diabetic patients. Int $J$ Nurs Pract 14, 40-46.

Mwebaza I, Katende G, Groves S \& Nankumbi J (2014): Nurses' knowledge, practices, and barriers in care of patients with pressure ulcers in a Ugandan teaching hospital. Nursing research and practice 2014, 1-6.

Nash M (2009): Mental health nurses' diabetes care skills -- a training needs analysis. British Journal of Nursing 18, 626-630.

Olsen M, Granath A, Wharén P, Blom T \& Leksell J (2012): Perceived knowledge about diabetes among personnel in municipal care: a qualitative focus group interview study. European Diabetes Nursing 9, 52-55.

Onwuegbuzie AJ \& Collins KMT (2007): A typology of mixed methods sampling designs in social science research. The qualitative report 12, 281-316.

Oyetunde MO \& Famakinwa T (2014): Nurses' knowledge of contents of diabetes patient education in Ondo-state, Nigeria. Journal of Nursing Education and Practice 4, p9198.

Rejeh N, Ahmadi F, Mohammadi E, Anoosheh M \& Kazemnejad A (2008): Barriers to, and facilitators of post - operative pain management in Iranian nursing: a qualitative research study. Int Nurs Rev 55, 468-475.

Shiu ATY \& Wong RYM (2011): Diabetes foot care knowledge: a survey of registered nurses. Journal of clinical nursing 20, 2367-2370.

Tocchi C, McCorkle R \& Knobf MT (2015): Multidisciplinary specialty teams: A selfmanagement program for patients with advanced cancer. Journal of the advanced practitioner in oncology $\mathbf{6}, 408$.

Tol A, Alhani F, Shojaeazadeh D, Sharifirad G \& Moazam N (2015): An empowering approach to promote the quality of life and self-management among type 2 diabetic patients. Journal of education and health promotion 4, 1-8.

Whiting LS (2008): Semi-structured interviews: guidance for novice researchers. Nursing Standard 22, 35-40.

Yacoub M, Demeh W, Darawad M, Barr J, Saleh A \& Saleh M (2014): An assessment of diabetes - related knowledge among registered nurses working in hospitals in Jordan. Int Nurs Rev 61, 255-262.

Young JL (2011): Educating staff nurses on diabetes: knowledge enhancement. Medsurg Nursing 20, 143-150.

This article is protected by copyright. All rights reserved. 
Table 1: The steps of thematic analysis (Braun \& Clarke 2006)

\section{Steps Explanation}

1 Transcribe the tape-recorded interview data into written format, followed by close and extensive reading;

$2 \quad$ Create codes for each participant transcript using a software program (NVivo)

$3 \quad$ Use codes to develop themes by combining similar codes together

$4 \quad$ Review and read themes to capture the contours of the coded data

$5 \quad$ On-going analysis to refine and name the themes

6 Write the final report and supporting themes with selected participant quotes

This article is protected by copyright. All rights reserved. 


\section{Table 2: Participants' characteristics}

\begin{tabular}{l|lll}
\hline Gender & Department & Year of experience & Nationality \\
\hline Male & Cardiology & 7 years & Philippine \\
\hline Female & ENT & 10 years & Philippine \\
\hline Male & Neurology & 10 years & India \\
\hline Female & Surgical & 9 years & Philippine \\
\hline Female & Medical & 8 years & Saudi \\
\hline Female & Paediatric & 4 years & Saudi \\
\hline Female & Intensive care unit & 11 years & India \\
\hline Female & Orthopaedic & 7 years & Saudi \\
\hline Male & Ophthalmology & 8 years & Saudi \\
\hline Female & Oncology & 28 years & Philippine \\
\hline Female & Neuroscience & 8 years & India \\
\hline Female & Nephrology & 18 years & Philippine \\
\hline Male & Urology & 8 years & Philippine \\
\hline Female & Obstetric/gynaecology & 10 years & 28 years \\
\hline Female & Emergency & 4 years & Philippine \\
\hline Female & Neurosurgery & & Philippine \\
\hline
\end{tabular}

This article is protected by copyright. All rights reserved. 
Table 3: Summary of the study themes

\begin{tabular}{|c|c|c|}
\hline Themes Categories & Sub-Themes & Meaning Units \\
\hline \multirow[t]{2}{*}{$\begin{array}{l}\text { 1- Diabetes care and } \\
\text { education }\end{array}$} & $\begin{array}{l}\text { The reality of the nursing role } \\
\text { in diabetes care }\end{array}$ & $\begin{array}{ll}- & \text { Contributing to the initial assessment } \\
- & \text { Administering in-patients medications } \\
- & \text { Following up the treatment plans, hospital } \\
\text { policies and specialist team instructions } \\
\text { care } & \text { Contribution in practical aspects of diabetes }\end{array}$ \\
\hline & $\begin{array}{l}\text { Overlapping diabetes care } \\
\text { and education }\end{array}$ & $\begin{array}{l}\text { - Overlap with dietician in relation to diet } \\
\text { consultation and instruction } \\
\text { - Overlap with diabetes educators in relation to } \\
\text { self-care activities and other holistic care }\end{array}$ \\
\hline \multirow[b]{2}{*}{$\begin{array}{l}\text { 2- Barriers affecting } \\
\text { nurses' acquisition of } \\
\text { diabetes knowledge }\end{array}$} & Individual level & $\begin{array}{l}\text { - } \\
\text { Lack of interest in gaining new knowledge } \\
\text { diabetes continuing education programs } \\
\text { - } \quad \text { Lack of clinical experience } \\
\text { - } \quad \text { Family-related issues, and the lack of priority }\end{array}$ \\
\hline & Organisational level & $\begin{array}{l}\text { - } \\
\text { Lack of resources } \\
\text { Lack of access to relevant information } \\
\text { and high workloads } \\
\text { Lack of opportunities due to staff shortages } \\
\text { incentives } \\
\text { - } \quad \text { Difficult interact with other members of the } \\
\text { multidisciplinary healthcare team }\end{array}$ \\
\hline \multirow[t]{2}{*}{$\begin{array}{l}\text { 3- Factors supporting } \\
\text { nurses' acquisition of } \\
\text { diabetes knowledge }\end{array}$} & $\begin{array}{l}\text { Organisational factors to } \\
\text { enhance diabetes-related } \\
\text { knowledge }\end{array}$ & $\begin{array}{l}\text { - } \\
\text { exchange across professional groups } \\
\text { - } \quad \text { Support for continuing diabetes education } \\
\text { and training } \\
\text { - } \quad \text { Improve institutional resources, such as } \\
\text { increasing staffing numbers and expertise } \\
\text { - } \quad \text { Provide printed learning and materials }\end{array}$ \\
\hline & $\begin{array}{l}\text { Environmental factors to } \\
\text { enhance diabetes knowledge }\end{array}$ & $\begin{array}{l}\text { - Effective inter-and intra-professional } \\
\text { interaction, communication and collaboration }\end{array}$ \\
\hline
\end{tabular}

This article is protected by copyright. All rights reserved. 